\title{
De privatizaciones, impactos sociales y buenas y males razones...
}

Ciertamente, existe necesidad de modernizar el estado, pero la privatización es tan sólo una de las formas de hacerlo y no es, como lo han creído muchos que se quedan a nivel superficial, sinónimo de modernización. Como tampoco es válido pretender privatizar todo. Tiene algún sentido privatizar hoteles, ingenios, fábricas, etc., pero no privatizar instituciones relacionadas con los servicios públicos, especialmente en países en donde los niveles de pobreza son elevados y donde al hacerlo se afecta a esos seclores pobres.

Pero bien, ahora que se han comenzado a privatizar aquellas instituciones de servicio público de alta rentabilidad y con fuerte impacto en la vida nacional, seguramente se comprenda el por qué algunos nos oponíamos a esa visión mecánica de la privatización absoluta. Sin embargo, para hacerla más evidente nos ocuparemos de dos casos de privatización: una real, ya efectuada y a nuestro juicio muy irracional, que es la distribución de energía eléctrica. La otra es tan sólo una propuesta, que puede ser considerada absurda pero que cumple con los requisitos de racionalidad empleados en otros casos, y se trala de la privatización de los vehículos nacionales.

\section{El sistema se sincera}

Con las nuevas tarifas de energía eléctrica, el sistema se sincera y establece que los subsidios se acabaron y que quien no tenga para pagar las nuevas y elevadas tarifas, pues, que no consuma energía eléctrica. Esto es lo que se llama vivir en de- mocracia y a nadie se le puede obligar a nada: si usted no tiene para pagar la luz, está en libertad de no usarla, usted tiene todo el derecho de pedir que le corten los alambres de su casa antes de que se le "pelen" los suyos pensando en cómo pagar las nuevas tarifas de Casamiquela. Aunque para esta gracia, mejor hubieran dejado a don Orlando al frente de la SIGET, porque de todas maneras ni se va a poder ver la televisión, entonces para qué la queremos.

Los precios se han sincerado y ahora los nuevos dueños cobrarán en realidad lo que realmente vale el servicio, y éste es bien caro; claro, porque los inversionistas extranjeros deben recuperar su inversión más una buena ganancia, de modo que si antes se pagaba 20 por algo que en realidad valía 80 colones, ahora se tendrá que pagar el precio sincerado'. Si puede... si quiere... porque esto no es obligación. Al fin y al cabo se puede vivir sin luz, pero no sin radio.

La culpa de que antes se pagara bien poco y que nadie esté acostumbrado a pagar realmente lo que vale el servicio es del "populismo y la demagogia", dijo un gerente de la SIGET. Esto es, la Superintendencia de Electricidad y Telecomunicaciones que fue disputada entre don Orlando y Casamiquela y que sirvió para demostrar que en el país existe independencia de órganos, y que la Corte Suprema de Justicia no le obedece sumisamente al Ejecutivo, pero que don Orlando aunque le ganó en la Corte a Casamiquela, terminó perdiendo la oportunidad y ya no pudo venderse el Canal 8. 
¡La SIGET, una entidad estatal técnica, no tiene respuestas para el reclamo generalizado por el aumento de tarifas y prefiere llamarlas "reacomodos". Si embargo, es claro que son alzas y además son inevitables! (Las admiraciones y las cursivas son del autor, lo demás es del redactor de nacionales de La Prensa Gráfica.)

Los reacomodos ocurrirán entre aquellos que no puedan pagar las nuevas tarifas y tengan que acudir a las candelas, los candiles de kerosene, las lámparas de carburo, al ocote, a las antorchas, las fogatas y todo para tratar de ver a dónde nos llevan los nada populistas, ni demagogos de ARENA y sus seguidores.

El aumento de "la luz" es el costo - político y para los bolsillos de los consumidores- de modernizar un sistema ineficiente que estaba en manos del monopolio de la CEL, que adicionalmente a su mandato original de generar energía, tuvo que hacerse cargo - por decreto- también de distribuir la energía, sin ninguna experiencia o preparación técnica, a partir de 1986.

Realmente no deja de sorprender esta actitud tan poco profesional del redactor -0 peor aún si es la línea del periódico-, porque la principal distribuidora de energía eléctrica en el país ha sido la CAESS, la cual era una empresa privada a la que se le venció la concesión en 1986, y fue igual de eficiente antes y después de esa fecha. Respecto a la CEL, inclusive, durante los años de la guerra fue un modelo de eficiencia, es más, ninguna empresa privada hubiera podido sobrevivir siendo como fue sometida a los ataques de la guerrilla. De modo que las afirmaciones mentirosas del señor redactor, lo único que revelan es su poca calidad profesional y/o los compromisos pagos del periódico.

Pero las afirmaciones maravillosas de la SIGET, fielmente registradas y complementadas por el periódico, continúan:

Cuando el nuevo modelo privado agarre impulso, espera la SIGET, el cobro en los recibos deberá bajar, a medida que las distribuidoras se peleen el mercado. La guena de disminución de precios llegará algún día, promete la SIGET.

Realmente lo que cabe esperar, como lo señalamos desde la primera vez que nos ocupamos de la temática de la privatización en 1989, es que los precios se incrementen, y ello es así por la sencilla razón de que el capital busca valorizarse o, si se prefiere, el buen capitalista busca actuar conforme a la lógica del capital, esto es, obtener mayores ganancias, y si para hacerlo es necesario sincerar los precios, pues los incrementarán si los márgenes que obtienen no son lo suficientemente atractivos, entiéndase elevados. Aunque decir: "yo se los dije" se considera de mala educación, ¡YO SE LOS DIJE!

Aunque el redactor de nacionales piensa -0 , ¿la SIGET? - que el mercado de energía es como el mercado de tomates, mangos o limones en cosecha y que algún día habrá algo así como una guerra de precios, que de venir de Casamiquela tal afirmación, ciertamente, para qué queremos un superintendente!

Pero el incremento tarifario entre los pobres no debe ser motivo de preocupación. El sistema se sincera y lo que para unos es pérdida para otros es ganancia, así nos lo dice la SIGET o, ¿La Prensa?

Con el nuevo esquema tarifario también hay ganadores inmediatos: la gran industria. Los centros comerciales (sic) fábricas, hoteles y otros grandes consumidores verán una disminución - en teoría - de sus recibos, porque la "sinceración" significa pagar menos por cada kilovatio de energía consumido, lo cual se traduce en ahorro cuando el consumo es grande.

De manera que no hay motivo para molestarnos, agradecidos deberíamos estar de que por fin el sistema se sincera y el ahorro lo verá si consume mucha energía, aunque La Prensa Gráfica, o ¿la SIGET?, contradictoriamente nos recomiendan ahorrar energía para pagar menos. Recomendaciones que ciertamente no son muy efectivas $y$, por tal razón, nosotros decidimos modificarlas un poquito, veamos.

\section{Cómo ahorrar energía}

* Planche con carbón. * No encienda ni un foco entre 6 y 11 de la noche. * Quiebre los focos que no utiliza. * Use candelas en lugar de focos. * Si utiliza energía para cocinar, ya no lo haga. * Si tiene horno de microondas, desconéctelo y úselo como panera. * Nunca abra la refrigeradora. * Los aparatos que más energía consumen son la cocina eléctrica, la plancha, el horno de microondas, la secadora de pelo, la cisterna (sic) y la refrigeradora. ¡DESHAGASE DE ELLOS... NO SABOTEE LA RAZON! 
Cualquiera pudiera pensar que con esto de la sinceración de los precios del servicio de energía eléctrica algunos, la mayoría, hemos salido fregados. $\mathrm{Y}$ eso que aún no se privatiza la CEL, la generadora de energía eléctrica, porque entonces el "socón" va a ser todavía peor. Pero no, realmente hemos salido favorecidos, lo que pasa es que sólo vemos lo negativo de las cosas. Pero para mostrarnos lo positivo ahí está la SIGET, o ¿La Prensa Gráfica?

\section{La ganancia del consumidor}

- "El consumidor puede buscar el mejor precio y negociar el servicio de energía eléctrica..." Como si pudiera llevarse su bolsada de energía, como si se tratara de comprar carbón.

- "Si le cortan el servicio por tres horas - por ejemplo-, la compañía tiene que descontarle el doble de lo que cuestan esas tres horas, en los próximos tres recibos." Además de la oscuridad: ¿descontarle tres veces el doble, o descontarle el doble repartido en tres recibos? El problema que se vislumbra es, ¿cómo le comprueba a la compañía que no tuvo servicio durante un determinado tiempo si la compañía lo niega?

- Reposición de artefactos arruinados por cambio en el voltaje, lectura mensual del contador, cobros excesivos, rebajas por figura llamada RMS, etc.

Ciertamente, cualquiera de estas virtuales "ganancias" se pudieron haber obtenido con tan sólo legislar al respecto. Si ésta fuese la razón para privatizar, realmente no habría razón para hacerlo.

Si la razón hubiera sido ahorrar o usar racionalmente nuestros recursos, obviamente bien se hubieran podido incrementar las tarifas sin necesidad de privatizar, es más, hasta se pudo haber destinado el incremento a recuperar la vegetación alrededor de los embalses y prolongar así su vida útil. Pero es claro que las razones fueron otras, esto es, las ganancias pero no las del consumidor, sino las únicas valederas, las de los empresarios capitalistas. Porque como lo dice un articulista de El Diario de Hoy, de buscar impedir el alza en las tarifas:

Peligra ... la venta de GTE-ANTEL, puertos, aeropuertos y la misma generación de energía. 
se hace de los vehículos nacionales. Al punto que un funcionario del Ministerio de Hacienda poco versado en asuntos políticos, pero con muchas ínfulas, propias de todo burócrata, al haber descubierto in fraganti a un empleado de dicho ministerio manifestó: "Desafortunadamente como director no puedo tener control total sobre lo que hacen más de mil empleados bajo mi cargo."

Ciertamente, nadie le pide control total sobre los empleados, sino que controle el mal uso de los vehículos oficiales que hacen los empleados bajo su cargo. Y si el argumento justificativo fuera decir que no se tiene control total, nunca existiría responsabilidad por ninguna acción indebida, ya que independientemente de la que fuera, siempre cabría argumentar que no se tiene control total.

Entonces, el punto por discemir debería ser el de que si alguien no es capaz de controlar a los empleados bajo su cargo, está ocupando indebidamente el puesto, puesto que si el argumento justificativo de incapacidad fuera el número de personas que se tiene bajo control, no existirían jefes superiores y los generales estarían ya descontinuados, aunque algunos ya lo están, pero por otras razones que no vienen al caso.

Sin embargo, en esto como en otras muchas cosas, lo que diferencia una postura radical de la de aquellos, a quienes a falta de un mejor calificativo llamaremos los remendones, es que el radical busca eliminar el mal de raíz, mientras que el remendón se conforma con tan sólo remendarlo. (¡Vaya que explicación más profunda!)

Así, en el caso que nos ocupa, el de los vehículos oficiales, más que estar denunciando el uso abusivo de los mismos, lo que se debería hacer es eliminar los vehículos nacionales, esto es, privatizarlos. Excepción hecha, por supuesto, a unas cuantas instituciones en las que por su misma naturaleza requieren del uso de vehículos oficiales, como la Policía Nacional Civil, los bomberos, los hospitales (ambulancias) y las presidencias de la República, de la Asamblea Legislativa y de la Corte Suprema de Justicia, por cuestión de estatus. Pero el resto de funcionarios del ejecutivo, judicial y legislativo es una total y absoluta estupidez que usen vehículos oficiales, ¿por qué y para qué se van a derrochar nuestros impuestos eñ la compra de vehículos, gasolina, repuestos, servicios y pago de motoristas? Si a un simple diputado se le asignan 3000 colones al mes, ¿cuánto le asignarán a los directores, viceministros y ministros? ¡El deroche es galán, de eso no hay duda!

Si el funcionario o empleado público quiere utilizar vehículo, pues, al igual que lo hacemos todos los que no vivimos del erario público, que lo pague de su bolsillo. Si no sabe manejar o no le gusta hacerlo, pues, que pague motorista. Esto no tiene nada de terrible, $y$ hasta se les podría asignar un determinado porcentaje del suelo para gastos de transporte cuando la misión oficial o la naturaleza del trabajo así lo exigiera. De lo contrario, para eso tienen sueldos harto jugosos, y si no es éste el caso, pues, que se busquen otro trabajo o que no usen vehículo, al fin y al cabo, cuantos menos usemos vehículo particular, menor será el daño que se le infrinja al ecosistema.

Además, el que los empleados y funcionarios públicos asumieran sus gastos de transporte, posibilitaría hacer un uso eficiente de los recursos, ya que el vehículo del señor director ya no se utilizaría para llevar a la muchacha al súper, ni los niños al colegio, ni la mujer al salón, ni la suegra de visita, etc. Y de hacerlo, sentirían lo cara que está la gasolina, ya no digamos los repuestos, y alguna continencia practicarían. Verían que no es lo mismo ordenarle al motorista que le llenen el tanque al $4 \times 4$ en la oficina, que tener que sacar la chequera o la tarjeta cada vez que se va a la gasolinera. Y ya no serían tan complacientes con el uso del vehículo. Lo que cuesta se cuida. Y el que quiere celeste pues que le cueste.

Lo triste y lamentable en nuestros países es que aún persisten resabios coloniales y los gobernantes se sienten depositarios de derechos monárquicos y divinos, los cuales se deslizan hacia los ministros, a los directores, hasta rodar por toda la escalera burocrática, de allí que cualquier funcionario o empleado público -incluso a nivel gatunose siente poseedor de innumerables derechos, entre ellos, el de no afectar sus alcoholizados nervios al conducir en día lunes por la mañana por esas tortuosas calles de San Salvador, que para eso está el motorista y el alcalde Silva, que es como que no existiera mientras no logre incrementar los impuestos y con ellos los ingresos para mejorar la capital.

Si el empleado o funcionario le pagara al motorista de su bolsillo sería su problema, pero como no es así, como se le paga con nuestros impuestos, el problema es nuestro. No es chiste que el gobier- 
no se lleve de los doce sueldos que ganamos casi dos para mantener a tanto inútil. Pero el abuso del empleado o funcionario público montado en su vehículo $4 \times 4$, polarizado y con aire acondicionado, no se reduce al desperdicio de los fondos públicos, sino al hecho de que cabalga por esas calles de Dios, como si las mismas se hubiesen construido tan sólo para los burócratas, ya que no respetan los derechos de otros automovilistas y mucho menos los de los pobres peatones, que al no ser motorizados evidencian su pobreza y carencia de derechos en esta maravillosa sociedad en transición a la democracia, esto es, al reino de las oportunidades. Donde la privatización debería afectar a aquellas actividades que le significan gastos al gobierno, esto es, a la sociedad, a nosotros los contribuyentes, y no a aquellas que generan ingresos como las comunicaciones, la energía, el agua, etc.

Quizá hasta podría parecer curioso que en la empresa privada, donde los trabajadores trabajan y los empresarios amasan grandes fortunas, sean raros y contados los empleados que disponen de automóvil con motorista pagado por la empresa; de ocurrir el caso se presenta como excepcional. Pero nadie se siente menos por conducir personalmente su vehículo, en cambio el burócrata es capaz de no ir a trabajar si por desgracia se enferma el motorista y no llega a recogerlo, a pesar de tener estacionado su vehículo en la cochera.

Nos parece que no es válido sostener que bastaría con llevar un control efectivo sobre los vehículos para que se les diera el uso debido, cuando no es cierto que exista algo así como un uso debido. Si la mera existencia de vehículos nacionales para cualquier actividad gubernamental es ya un acto incorrecto e indebido, no puede cambiar su calidad por el hecho de que se tenga sobre los mismos un determinado control, por muy eficiente que éste sea. Al fin y al cabo, el mejor control es aquél que no se hace $y$, por tanto, al venderle a sus usuarios los vehículos nacionales, se haría el mejor control sobre los mismos.

La postura controladora o remendona se corresponde con las intenciones de El Diario de Hoy, porque el periódico de marras en ningún momento busca resolver un problema, sino desprestigiar a un determinado partido político en el poder, del cual dicen estar desencantados algunos de sus fundadores. ¡Pobres los pobres ricos, crearon cuervos para que les sacaran del partido! La crítica que hace el matutino de hoy -con visiones ideológi- cas de ayer- al gobierno central por el abuso que se hace de los vehículos, no difiere mucho de las críticas hechas al alcalde Silva, por buscar incrementar la tributación de los ricos para mejorar la ciudad de San Salvador. En el fondo, les hermana la doble intencionalidad por más que la busquen disfrazar de patriotismo, nacionalismo, economicismo, mercantilismo, pinochetismo, etc.

Diferente es la postura del radical, quien en su afán honesto de cambiar la irracionalidad en las cosas y la injusticia de la acciones humanas, a menudo se aproxima con sus planteamientos a las posturas anarquistas, lo cual no debería ser motivo de preocupación, ya que también en el anarquismo existe sabiduría. Razón por la que al seguir tal linea de pensamiento se podría decir: "que el poder como que lleva en sí mismo la exigencia de corromper a quien lo detenta, razón por la cual, lo más sano y saludable seguramente sea la ausencia de poderes, al menos, los poderes políticos".

Los derechistas sostienen que para evitar la corrupción es preciso eliminar aquello que la posibilita. Así, la privatización aparece como la gran medicina. Ciertamente si no hay que robar no podrán haber ladrones. Hasta en los textos sagrados se dice que "en arca abierta hasta el justo peca". Pues la misma lógica que han empleado para privatizar, casi todo lo privatizable, deberían aplicarla a los vehículos oficiales, y así de paso evitarían el robo de gasolina, diesel y repuestos.

De seguir así, recortando y recortando gastos, habría esperanzas de que algún día a principios del tercer milenio, nos rebajaran los impuestos a los empleados, que entre impuestos directos e indirectos nos cargan cerca del 50 por ciento de los ingresos, y por esto no protesta la ANEP, ni los banqueros, ni los chilenos, ni nadie... Sufrimos en silencio, como quien va al matadero y sabe la maldita suerte que le espera.

En el año de la visita del Santo Padre a Cuba - y confiando en que ésta no corra la misma suerte que Polonia-, y en el mismo año de la amenaza de la Tercera Guerra Mundial, gracias a la impúdica intención de distraer la atención en los amores de Clinton y el ánimo fatalista de que se cumpla la última profecía de Nostradamus, les decimos: ¿y por qué no privatizan también los vehículos oficiales, la defensa nacional, los monumentos patrios, el guarón y la Dirección de Cultura?

Aquiles Montoya 